\title{
The Storyboard as A Means of Translating Narrations and Concepts into an Animated Web Series
}

\author{
Jesús Alejandro Guzmán Ramírez ${ }^{1 *}$ and Fredy Germán Jiménez Bogoyá ${ }^{2}$ \\ ${ }^{1}$ School of design, photography and Audiovisual realization, Jorge Tadeo Lozano University, USA \\ ${ }^{2}$ Graphic Designer, Jorge Tadeo Lozano University, USA
}

*Corresponding author: Jesús Alejandro Guzmán Ramírez, Associate professor, School of design, photography and Audiovisual realization, Jorge Tadeo Lozano University, Bogotá, Colombia, USA

\begin{abstract}
The present document develops primarily the concept of storyboard, its origin and relationship with the concept art and its impact within a flow of production, drawing on theoretical foundations from the history of art, the history of animation, the sketching like a design process, the cognitive development, animation "limited" and the web series, reflecting the development of the storyboard that will serve as the basis for the realization of the pilot of the animated web series "Chronicles of the Edge of the World", which is based on the Latin American historical memory of the pre-hispanic period and of the conquest reinterpreting historical accounts.
\end{abstract}

Keywords: Storyboard; Graphic Script; Illustrations; Animated Drawing; Computer Design

\section{Introduction}

\section{The storyboard as part of the process of concept design}

In the pre-production stage of an animated project, framed within the concept design, the storyboard is considered as one of the most important elements of development, because it is the visual construction of standard language in all the rest of the production. In the following document, analyzes the process of elaboration of the storyboard presenting its historical background and its establishment because of a design process, and it should be borne in mind by the technological aspects and characteristics of the profiles of the team with that it accounts for the realization of the project allows you to produce an adequate storyboard. In this case, practical experience is taken as the development of the pilot episode of the animated web series "Chronicles of the Edge of the World", which is based on the Latin American historical memory of the pre-hispanic period and conquest, dystopian way of interpreting historical accounts.

The term Storyboard is a word of Anglo-Saxon origin that has been appropriate in the Latin American lexicon, its literal translation is graphic script (Cambridge Dictionary 26/01/17), semantically speaking the Spanish translation of this term is not distance from its English origin, as is the case with the term concept art, which formally translated means Conceptual Art, taking into account that the term concept art is used to refer to development processes in areas such as the illustration and animation, where the storyboard is included because it is part of the process of conceptual development of pre-production, it is necessary to make some clarifications on the implications of the translation of the term concept art into Spanish.

The Conceptual Art in the field of Arts is understood as the artistic current that developed at the end of the 1960s and 1970s, whose objective is to give priority to the idea over the conduct formal or material of the work; the approaches of conceptual art, in the words of Vasquez Rocca [1] determine that the "real" work of art is not the physical object produced by the artist but consists of "concepts" and "ideas"; giving an iconoclastic character in himself that "emphasizes the elimination of the art object in its traditional forms. [...] Shift the emphasis on the object ("material") in favor of the conception and project, behavioral, perceptual, imaginative or creative of the receiver. In this way the literal translation of the term "Concept Art" does not correspond to the processes and conceptions of the illustration to develop a visual system, which must respond to specific production needs, for this reason the term is closer to "Design" as the meaning of development process that the art as a form of expression. 
Considering the difference established between conceptual art and concept design, it is proposed to replace the word "art", by "design" for this meaning. According to César González Ochoa [2], the "Design" gives an account of the mental processes involved in the development of an idea based on experiences, where there are a series of presuppositions and implicatures that must handle both the designer or creative, as the recipient of the message. According to the above, make sense is one of the purposes of the design; this creation of meaning involves conceptualizing the contents that are created, that is to say, from a perspective abstract knowledge of the "world", which is based on the experiences and interpretations aware of the context, thus generating a realization through a manual expression, going to different technical tools, this way it makes it look and feel to the receiver of the message each and every one of the elements with which that content makes sense as the best response to a question, problem or need.

The importance of establishing this concept as a starting point has to do with the type of context in which it develops this research, and where the visual results are produced in the framework of the construction of meaning at the same time generate pieces that fall into the category of Concept Art, and when you are looking for a definition, usually falls into errors or inaccuracies that may affect the sense of what is meant by evidence, and that in the spirit of establishing reflections within a developing field for Colombia as it is animated production, it is necessary to begin to establish a conceptual north to resolve any doubts and keep in If the same approach that articulates the processes of implementation.

\section{From the idea to the production of audiovisual "language"}

When the designer materializes the concepts and ideas, this creator takes basic elements of the form (point, line, plane) which are equipped with a specific function, either as lines of composition of plane, or as elements of construction, that is, each element is endowed with a meaning. Based on the above, you will reach the initial sketch, like a realization of the idea that was conceived in the conceptualization; through the sketch the individual understands the phenomena observed, reinterprets and structuring a progressive solution to a specific problem, facilitating in the designer [3]"the will to understand the reality," which should be interpreted by the conceptualizador through the process of cataloguing, characterize, classify, and apply nomenclatures.

Considering that the mission of a storyboard artist is to convey the vision of the director, create a storyboard is one of the processes of generation of ideas where the greatest feature of the sketch and the evolution of the same is the translation of a narrative or written language expression (understood as a literary script or story of a situation) to a series of sequential images that realize that description. To transmit the information provided by the script and translate it into a preview of three-dimensional space in a twodimensional medium, it makes use of both semantic associations (words) found as annotations and specifications; and pictorial associations [4].
As stated above, the draft or sketching is an act inherent to the design, which allows you to realize ideas and display a dialog between them and their evolution. Development that is based on the materialization of concepts from a state of abstract ideas from, as Dan Torres writes [5] The generation of a cluster of "layers" of work, both conceptual and materials, which have a unique set of processes that allow the comprehension and the reinterpretation of reality; at this point we can establish that the elaboration of the materialization of concepts the process can be more important than the result itself, this it is submitted, taking into account the philosophy of the process [5], which emphasizes the concepts of time and flow, without diminishing the importance of the elements and material objects, but that drives the approach of that behind every item that we perceive there are specific processes and logical for such a result. Thus, considering the cognitive development, which stated that the knowledge evolves from less complex structures to more complex structures, is considered pertinent to understand the process of elaboration of the storyboard, consider the conceptual development of the storyboard in the three phases or levels of detail raised by Andrew Selby [6].

In the first phase, the creator of the storyboard downloads on a surface using his tool of choice, in the form of thumbnail sketches, the random thoughts that may lead to a chain of sequential images. At this point in the development the intention and the narrative are above the purity and cleanliness of the expression, as it seeks to find the proper way to preview the scenes, the framing and how to encourage the development of history through transitions and camera movements, which will help to evoke the mood and atmosphere of the story. In a second phase, the draft miniature approved develops in a larger size, adding details to the scene, and giving more information on possible camera movements. At this point is where the understanding of the process of the evolution of "language" that starts to raise and refine the components of the audiovisual grammar that begin to convey a message in the middle of the production flow. In the third place, a version is created, or a presentation with additional tables to populate the aspects between the boxes that mark the keyframes. This part acts as a solid visual framework and reference for the animatic and allows the inclusion of provisional dialogs and a trial version of the soundtrack, which creates a draft of the project.

Technically speaking the definition of Storyboard or graphic script is set as the group of sketches, illustrations or keyframes presented sequentially with the aim of presenting an idea. Although it is a reference to Walt Disney as the first industrial scale use the storyboard between 1920 and $1930^{1}$ [6], we may find clues to the origin of the storyboard in numerous medieval illuminated manuscripts and books. One of the main examples of this practice is the text of Sigenot, an epic cavalier attitude toward 1558, which is account as shown on each page. The images are connected by the illusion of movement, flipping through the pages of the manuscript is some illusion of dynamic, although there is no evidence that this was the original intent [7].

${ }^{1}$ In the production of the Disney studios, the storyboard is seen not only as a vital tool of communication between the animation teams who are involved in the production, but also to test ideas risky to create stories with potential to stage of production, thus avoiding risking large amounts of money, without having the certainty to recover it. 
We can also detect as an ancestor of the storyboard, simplified visual language of the comic, which through comic strips, sequential panels and the use of iconographic symbols sought to convey with greater emphasis the actions and the anticipation of movements; in fact, the first characters of animated films were taken from comic strips of printed media and many animators launched their careers as creators of comic strips (MacCay, Disney, Terry, Miyazaki, Groening, etc) [7].

This evidence of the origin of the storyboard show that both the Content Generators and receivers of the same must have clear codes of interpretation. The images of the text Sigenot and simplified the language of the comic respond to specific needs in specific contexts. The medieval story is shown in full pages and is used more number of images of texts because the amount of people at that time, they could understand texts were very few relatively, in contrast the images were easier to interpret by most members of society, as well did not have instruction in reading. On the contrary, consumers are people who could read, not only to understand narrative lines or dialogs, but also can interpret the onomatopoeia that give the printed content of sound, which although not be perceived physically by the ears of the readers, if it allows a greater connection with the story.

In this same way, the illustrator that generates the storyboard must use codes in their previews, these codes must obey the context in which it interpreted the storyboard the semantic associations (words) and signs that use the illustrator must be understood by the team that will develop the project. Only in this way will the translation between the base narrative or literary script and storyboard will be effective and functional, in other words, if the language of the director of the storyboard is akin to the work team, the people who have contact with this part will have the capacity to interpret signs and contents that are there ready.
Considering that the product is the result of the union of the labor force and a wealth of artistic personalities [8], the communication between each and every one of these personalities or profiles, is essential for the production line to achieve its task with respect to the established times. Taking this into account, the storyboard is a fundamental tool for the communication of directors with their teams of preproduction, production and postproduction, since through this storyboard sets the conceptual basis and the schema on which will develop the necessary elements for the overall production. The illustrator that develops the storyboard must maintain a constant dialog with all the members of the production, so you will have the ability to know in depth the developments that are being generated and the specific details of the references that we have; this will allow you to capture the essence of every aspect and focus on the development of the storyboard in the indicated direction.

At the end of this storyboard, after being approved by the directors of the project, it is common to arrange printed on a wall or panel, where each of the involved have the possibility to get closer to display the storyboard both in a comprehensive manner, as each of the individuals of the same. This practice helps streamline workflows, as it allows a constant dialog between the members of the production team and development, encouraging an active dialog between the same, allowing the resolution of doubts and concerns in real time.

An example of this, is the willingness of the storyboard during the production and filming of the animated short "Atando Cabos" developed by the programs of Industrial Design and Graphic Design at the University of Bogotá Jorge Tadeo Lozano. In this project the storyboard was the main guide during the complete development of the same, and thanks to its proper development, allowed to complete the production with the required quality and respecting the times prepared for that purpose (Figures 1 \& 2).

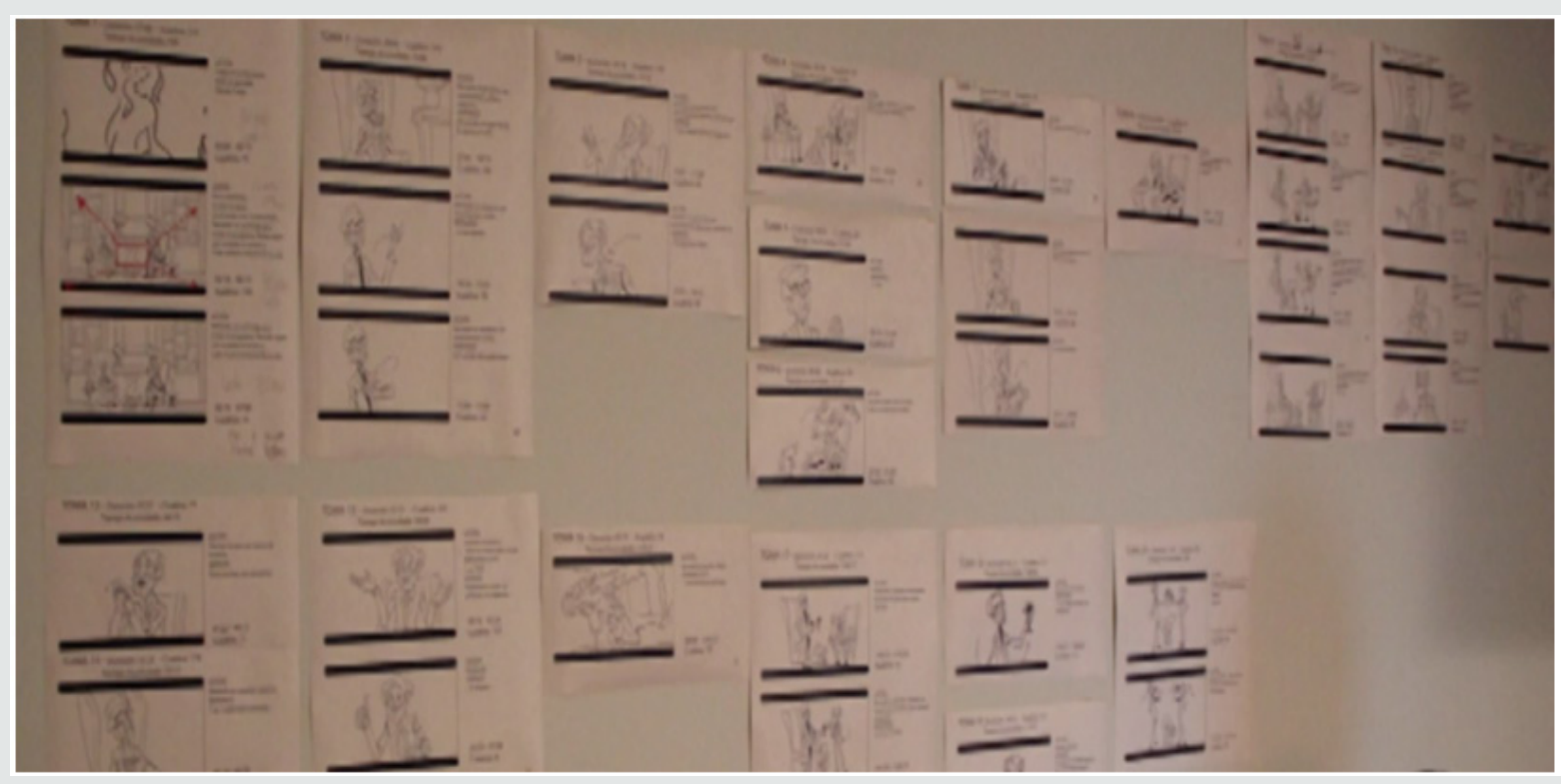

Figure 1: The disposal of the storyboard during the filming of "Atando Cabos" production. 

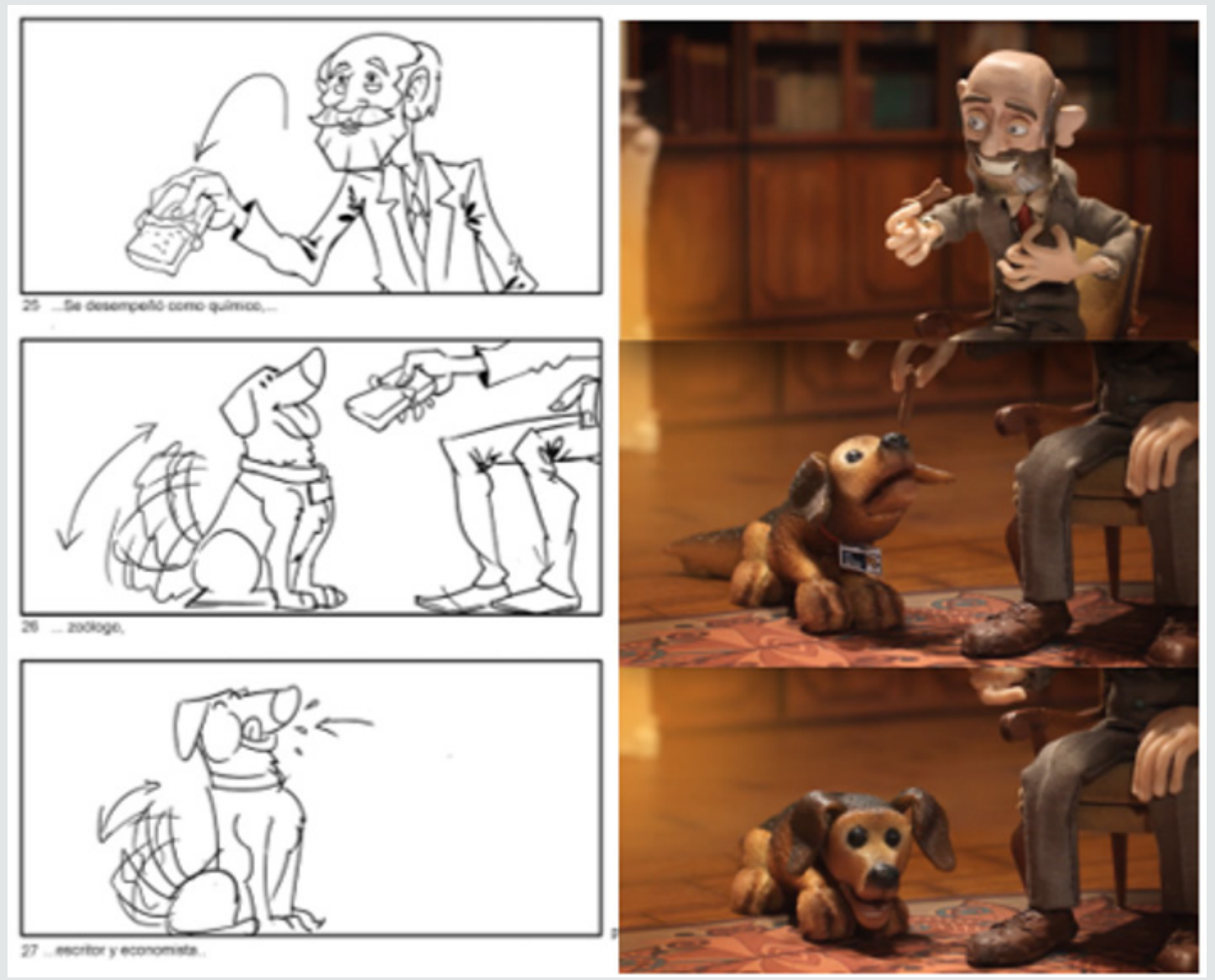

Figure 2: Section of the storyboard made by the illustrator Jorge Ávila and its corresponding implementation in the animated short film.

\section{From traditional media to digital media}

However, today, the development of animated content is not only limited to short films, feature films and television commercials, as it was ready until the end of the last century. The developments emerging from individuals or groups around the animated phenomenon ${ }^{2}$, are increasing due to the possibilities of the web, which is one of the resources has had more boom in recent years is to generate webseries which can be defined [9], "like all those serial fiction audiovisual productions designed to be disseminated on the Internet. with a storyline, with thematic continuity and more than three chapters."

This phenomenon was initiated by the producers of television content, who stayed contained in its pages of the internet to expand its presence in the media, allowing viewers to interact with the content that produced [10], this alternative has been used by independent content producers to present their work and distribute it at a much lower cost compared to the cost of distribution in the traditional means, in addition to concentrate its attention and resources on the web and mobile content, it is possible to reach more effectively to the target audience.
The possibility of generating audiovisual content with a low economic investment and considering the increase in connectivity and quality of the services of communication network at the global level, has allowed a process of democratization both in the information that is disseminated, such as who issued, thus overcoming the unilateral communication of traditional media. These characteristics [10] (Morante and Hernandez (2012) cite to Castells (2001), represent a paradigm shift in the communication process and, through him, of culture in general.

Based on the benefits of the distribution of content on the web, and occasionally in response to the question "what content can be directed to public youth? Made by Barron Domínguez and Hernandez de Lago [11] (2013), leads to the creation of the animated web series "Chronicles of the Edge of the World", in which the re-interpreted historical accounts of the pre-hispanic period and conquest, appearing in a timeless context that enables it to generate a different way of bringing this cultural content to the society now immersed in the web. This proposal is made based on what Thomas Lamarre [12] (2002) called limited animation, which holds that a narrative construction and plot strong enough, will

${ }^{2}$ As evidenced by the example "Atando Cabos" where two programs of one of the first universities which came to study the phenomenon in Colombia academically, joined together to develop a piece animated to deepen in the manner in which they could develop structures for animation stop motion with materials and elements to be found in the Colombian market. 
take viewers to immerse themselves in the history regardless of the techno-artistic limitations that may occur.

\section{A proposal anchored in the context}

For the development of the project "Chronicles of the edge of the world" the production account with a working group formed in their majority by illustrators. The teams that are working to respond successfully to the development of the design of the general concept, but do not allow a three-dimensional modeling of high complexity, because they are not structured machines for a high burden of work. In view of the above, it is posed by the development of the general aesthetic of the project based on the enlightenment and in the texturing of surfaces of low complexity, demanding as well to developers of argument in the history of outstanding work, that will captivate the audience taking advantage of the narrations and skills available to the working group.

The story that develops on the web series presents situations that reflect some of the events of conquest and miscegenation in the American continent. It is the story of Gonzalo Guerrero Aroza, a Spanish arcabucero that participates in one of the first trips to America, who due to various experiences change your way of thinking and eventually dies in combat as the leader of a native tribe against the Spaniards (Figure 3).

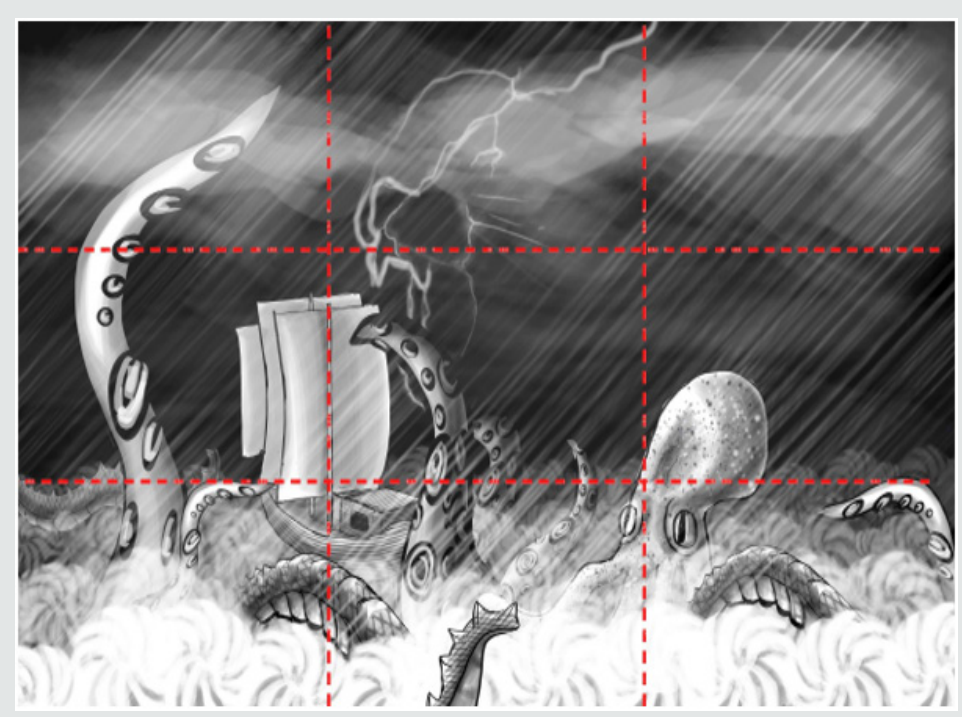

Figure 3: Illustration that makes up part of the storyboard for the web series' pilot "Chronicles of the Edge of the World", in this case, it makes use of the law of thirds to generate visual tension of the situation, in addition to the overlapping planes illustrated to generate depth.

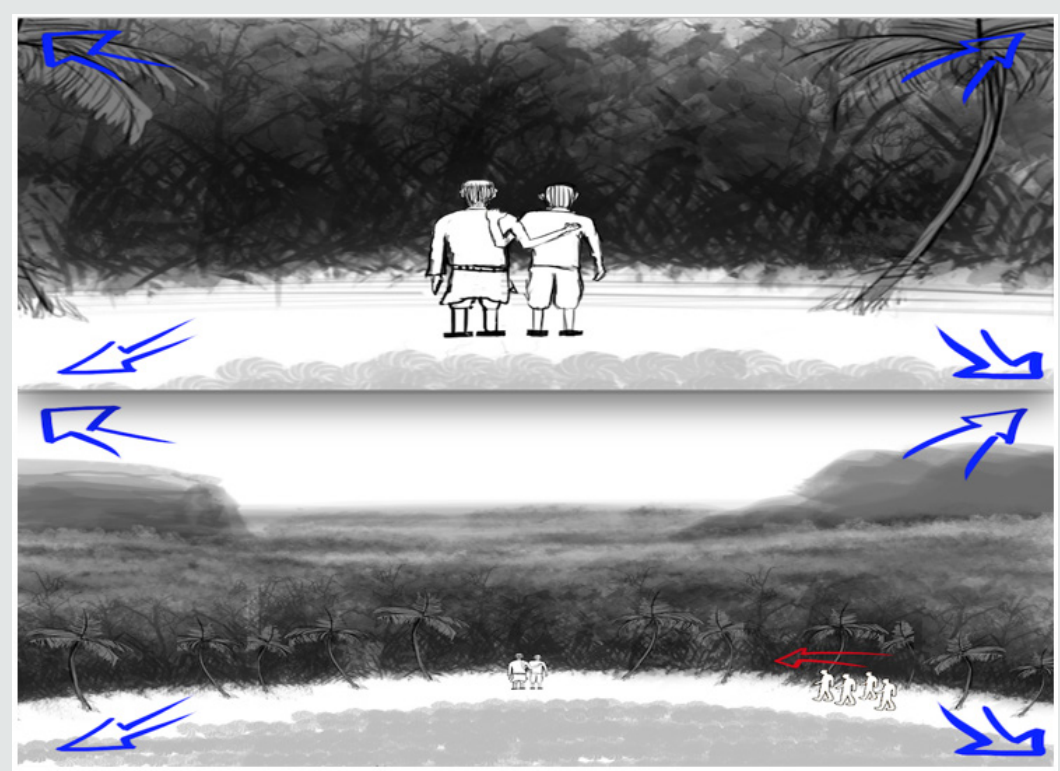

Figure 4: Illustrations that are part of the storyboard for the webseries' pilot "Chronicles of the Edge of the World", on this occasion, makes use of the zoom out narrative resources, allowing you to show the development of funds illustrated as an alternative to the generation of scenarios in 3D. 
Considering the technology available for the realization of the animation and the narrative generated by the writers, a storyboard that bases its structure in the use of the composition of scenes to transmit the sensations of the history, this reduces the need to use panning or camera movements that require a high generation of $3 \mathrm{D}$ elements. It also gave importance to the use of general plans energized by simple camera movements such as the zoom in and zoom out allowing to increase the use of the illustrated resource has been funded; and taking as a reference the anime ${ }^{3}$ for the moments of greater intensity and expressiveness of the characters, shows the face of these in the foreground, leaving a couple of frames to achieve the viewer's connection with the emotion that seeks to reflect on the scene (Figure 4).

\section{Methodology}

The present research is qualitative, and for its development was implemented the "design" of Bruno Munari, in which the investigative process of conceptual development is made from the reflection on the elements or processes generated manually, i.e. from the systematization of the experience, this allows you to compare the conceptual referents with parts that are developed in practice, allowing the construction of knowledge from the reflection of the praxis, and not only from an idealized theoretical approach.

Parallel to the development of the storyboard for the elaboration of the web series' pilot episode of the animated "Chronicles of the Edge of the World", an inquiry was made on the different aspects that are involved in the process of developing a storyboard and how the generation of this visual element has an impact on the overall process of elaboration of the draft.

In the process of creation of the storyboard, sought relating to come close to the results that they wanted to achieve with the development of the audiovisual piece, the most influential aesthetic referents were Marvel Knights Motion Animation (Marvel,2009), Mighty Antlers (The Animation Workshop, 2009), The Backwater Gospel (The Animation Workshop, 2011), and Phantasmagoria (Studio Freak, 2014). Animated Products which allowed starting points of how to generate narrative rhythms and dynamic composition of planes to give preponderance to the illustration as a visual resource above the $3 \mathrm{D}$ modeling. Among the most relevant thematic highlights the legend of El Dorado (DreamWorks Animation, 2000), Mel Gibson's Apocalypto (2006), and Moana (Disney, 2016), where the transmission of sensations in the middle of the jungle, the generation of depth in general plans and chromatic approaches were a great contribution to the development of this sequence.

To find the significant elements in the visual, the search is deepened in the light of the concepts that are developed in the theoretical references, searching the Internet processes of evolution and materialization of ideas and concepts of these productions, where it was demonstrated the great importance of the elaboration of a storyboard with an adequate handling of language and a clear visual rhythm that it managed to convey the feelings required, increasing in a large percentage the possibility of success of an animated production.

The final stage of development involved the production of the storyboard as a contrast of the concepts that are found throughout the investigation, allowing to develop the scheme of levels of refinement, and demonstrating the relevance of an evolutionary process in the production flow, providing dynamic relationship between what we want to count and the respective audiovisual product (Figure 5).

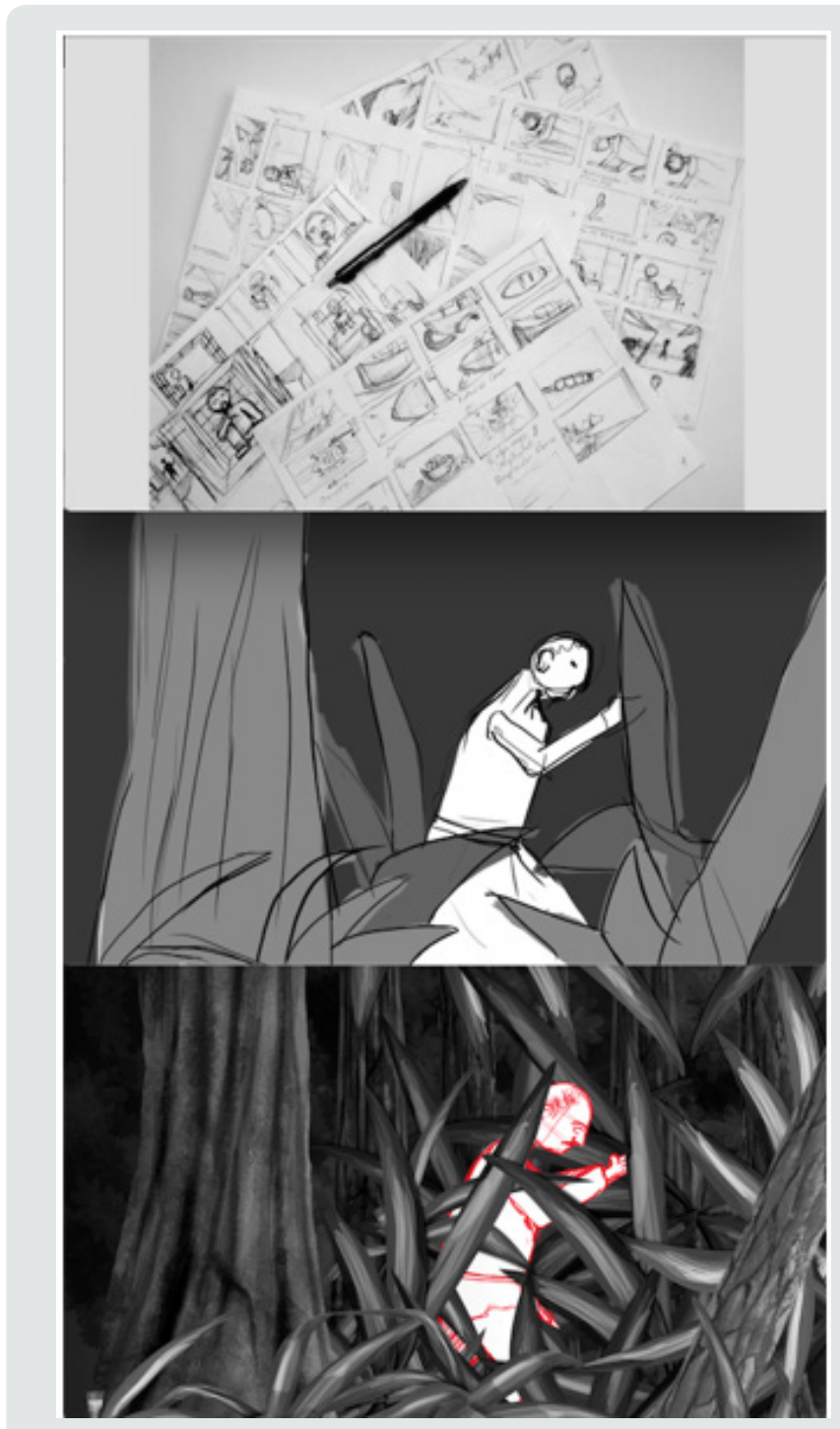

Figure 5: Development of scene from the storyboard using the methodology proposed by Andrew Selby.

\footnotetext{
${ }^{3}$ Current animated aesthetic that appeared during the japanese economic crisis of the years 60 , where financial constraints led to the animation studios to reduce the amount of animated frames ready for each production, that is to say, while in an animation "complete" an image remained on the screen for one or two frames in the animation "limited" this image was visualized by 5 or 6 frames where emphasis on facial expressions with resources such as the "trembling" of the stroke or the use of large funds illustrated on that moved the character, which saved the drawing frame by frame of all the same, this form of generating animation gave rise to what is known today as anime.
} 


\section{Findings}

A. From the development of the concepts storyboard and concept art, emerged several authors such as Ulo Pikkov [7], Thomas Lamarre [12] and Heather Holian [8], which allowed see the theoretical study of the animation as a field of knowledge that it is necessary to investigate and in which it is essential to deepen, because the animation is a cultural expression, which is mediated by technological artifacts. The evolution of these artifacts promotes new expressions and forms of generating and projecting the animation as a reflection both culture in which production is developed, as the elements with which it has achieved this result.

B. In the process of inquiry and search came to fields in which was not budgeted venture, as it was the case of cognitive development, where he found a great support in Dan Torre, who makes an analysis of the understanding of the animation from the relevance of the process, both to develop and to convey to the viewer the animation, how to understand that the animated phenomenon is a cognitive phenomenon that affects the psychological and physical behavior of the receiver, this emphasis on the conceptualization and the process allowed to associate the processes of development and conceptualization in the design with the generation of the storyboard or graphic script. In this way it is possible to confront with greater success that design is known as " the blank sheet", that is to say, to start the process of materialization of concepts and ideas on a surface without visual information, allowing the download of information, annotations and first drafts, are the main tool to carry out the conceptualization to its appropriate point on the materialization, which in the case of the development of the storyboard, is reflected in a very appropriate in the phases or stages of development or level of detail raised by Andrew Selby.

C. It is essential that before generating each scene from the Storyboard or graphic script, the Illustrator reflect and raised a series of questions that allow him to realize successfully the situations that presents the literary script or the narration, for example Who is involved in the scene? what location or scenario are located the characters? Why the characters are there? What emotion or attitude prevails in the scene? What position should the camera to emphasize the emotion that you want to convey appropriate? Is it a camera movement, why and what for? The technique in which the development of the project, allows this camera movement? What type of camera movement or composition of plane allows it to display in a better way the aesthetics of the project?
D. To find the source of the anime, that is to say, its development as a response to a technical and socio-economic situation in a particular context, that little by little he was being accepted by the audience and at the same time assimilated by a large number of artists, to become a current aesthetics of the animation, allows you to reflect on the limitations that at some points the filmmakers young people pose as obstacles, revealing that the recursion and the use of multiple techniques of expression, that is to say, the generation of different aesthetic in the animation, we can give through pictorial development, the improvement of the technical and above all, the construction of a narrative with a solid argument and innovative, without relying on expensive equipment and large investments of money.

\section{References}

1. Vasquez Rocca Adolfo (2013) Conceptual Art and posconceptual. The idea as art: Duchamp, Beuys, cage and fluxus. Universidad Complutense de Madrid, Madrid, Spain.

2. Ochoa C, Torres $\mathrm{M}$ The design and the human sciences. Toward a comprehensive approach.

3. Guzmán A, Rivers D (2016) The drawing as a model of constructive ideas and illustration as design process. Bogotá, Colombia, USA.

4. Shan Teng P, Cai D, TK Yu (2014) The relationship between individual characteristics: Suicidal ideation and behavior: An empirical study of storyboards. International Journal of Technology \& Design Education, Taiwan.

5. Torres Dan (2014) Cognitive Animation Theory: A process - Based Reading of Animation and Human Cognition. Sage Publications p. 42-64.

6. Selby Andrew (2013) The animation (Rodríguez, T). Barcelona, Blume, Spain.

7. Pikkov Ülo (2010) Animasophy-Theoretical Writings on the Animated Film. Estonia.

8. Holian Heather (2013) Art, Animation and the Collaborative Process. Animation Studies Online Journal 8.

9. Delgado Beatriz (2014) Traditional series web series Badajoz. University of Extremadura, Spain.

10. Morante F, Hernandez P (2012) The web series: Convergences and divergences in a pop-up format of the narrative in Network. Malaga, Spain.

11. Barron Dominguez L, Hernandez A (2013) Migration of audiovisual content of fiction to the mobile phone in Spanish speaking countries; web series and web novels. Reason and Word, Instituto Tecnológico y de Estudios Superiores de Monterrey, Mexico.

12. Lamarre Thomas (2002) From animation to anime: Drawing movements and moving drawings. Japan Forum 14(2): 329-367. 
CC (P) This work is licensed under Creative Commons Attribution 4.0 License

To Submit Your Article Click Here:

Submit Article

DOI: $10.32474 / J A A S .2020 .01 .000121$

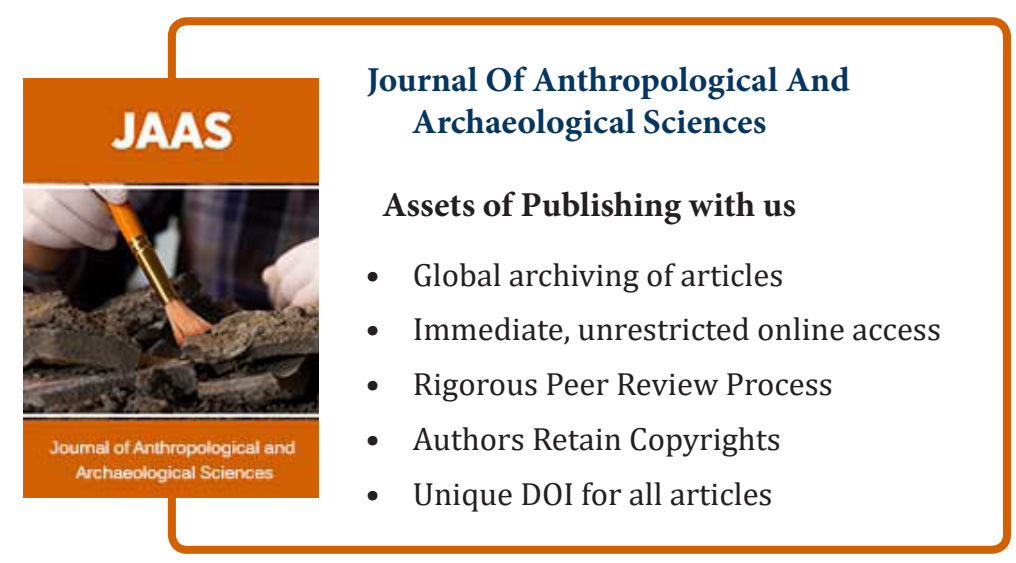

